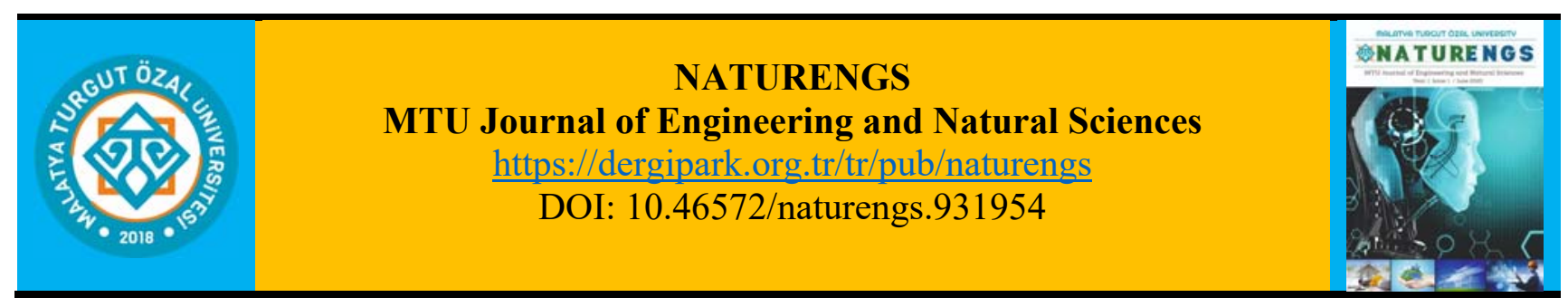

Research Article

\title{
Activation and Characterization of Unye (Ordu) Clay with Nitric Acid
}

\author{
Yeliz AKBULUT ${ }^{1 *}$, Yunus ÖNAL ${ }^{2}$ \\ ${ }^{1}$ Department of Chemical Engineering, Faculty of Engineering, Inönü University, Malatya, Turkey.
}

(Received: 03.05.2021; Accepted: 10.07.2021)

\begin{abstract}
In this study, clay belonging to the Ordu Unye region was activated by different concentrations of the acid solution by analytical methods. It is intended to remove adsorbed components between layers found in the structure of the clay. As a result, the activation process was performed with nitric acid $\left(\mathrm{HNO}_{3}\right)$ to enable the expansion of the distance between layers. Determination of structural changes of natural clay and activated clays have been characterized by XRD, SEM, FTIR and BET analyses. Characterization results showed that acid activation caused significant increases in surface area and pore volumes by changing both morphological and surface properties on clay. As a result of activation, the highest surface area of the clay was determined as $205.08 \mathrm{~m}^{2} / \mathrm{g}$ with $2 \mathrm{~N} \mathrm{HNO}_{3}$. Acid activation is more efficient in improving the surface properties of clay.
\end{abstract}

Keywords: Acid Activation, Clay, Surface Area.

\section{INTRODUCTION}

Clay is a sedimentary mineral formed by the decomposition of soft and very fine-grained feldspar, mica and other silicates, which contains high levels of $\mathrm{Al}_{2} \mathrm{O}_{3}$ and $\mathrm{SiO}_{2}$ components as the main component in its structure together with $\mathrm{MgO}, \mathrm{CaO}, \mathrm{Fe}_{3} \mathrm{O}_{4}, \mathrm{Na}_{2} \mathrm{O}, \mathrm{K}_{2} \mathrm{O}$ and $\mathrm{TiO}_{2}$. Clay minerals are filtration components of nature, provide rain and snow water to be filtered underground and transform into drinking water quality. Adsorption, hence the filtration property, has a major significance in the industrial usage of clay. Acid activation is often used to modify and/or improve the structural properties of clay minerals by adsorption [1]. Defining the chemical and physical properties of the surface layers of a material is called surface analysis [2]. High surface area, number, and size of pores, as well as the number of acidic zones in the structure, are important for clay minerals. Acids such as $\mathrm{HCl}, \mathrm{H}_{2} \mathrm{SO}_{4}, \mathrm{HNO}_{3}$ are therefore preferred for activation processes in different concentrations [3-7]. All clay minerals can be physically and chemically altered by acid activation [8-10]. Although these changes are adsorptive properties, they are an increase in surface acidity, surface area, porosity, and pore volume. It has been determined by many scientists that the charges on the surface and the distances between silica layers can be changed. [11-13]. With the acid treatment, the formation of Si-OH groups already present in the structure is promoted and the interaction of minerals with different species in solution can be increased. In this case, applications can become diverse. As a result, acid-activated clays are used in different application areas in the industry. Acid-activated clays are used in environmental improvement processes, wastewater treatment,

*Corresponding Author: yelizzakbulut@gmail.com

ORCID number of authors: ${ }^{1}$ 0000-0002-0703-7055, ${ }^{2}$ 0000-0001-6342-6816 
catalysis, sorption areas, oil refining, casting sand, drilling, filling, chemistry, detergent, cosmetics, paper, ceramic, pottery, faience, glass, porcelain, paint industries. [14-16]. Acid activation is easy as well as low cost. For this reason, many studies have used nitric acid as well as hydrochloric acid and sulfuric acid for the acid activation of vermiculite. [17-19]. Understanding the effect of acid activation on the structural properties of Unye bentonite is important for the use of clay-based commercial adsorbents or solid acid catalysts. [20-21]. As the main input agent in liquid oil refining and many other industrial areas, clays create a great economic potential. Acid activation improves the absorption properties of the clay by increasing the specific surface area as well as the active region. These changes depend on several factors, such as acid concentration, the nature of the clay, the duration of activation, and temperature.

This study aims to investigate the effect of different acid types $\left(\mathrm{HCl}\right.$ and $\mathrm{H}_{2} \mathrm{SO}_{4}$ preferred in the literature) using $\mathrm{HNO}_{3}$ at 0.5-3 $\mathrm{N}$ concentrations and to compare the final structural properties. XRD, SEM, FTIR, and BET analyses were used in the study. As a result of acid activation of bentonite taken from the Unye region of Ordu Province activated by nitric acid, it is aimed to improve the surface morphology and surface area changes of partially dissolved clay and contribute to the literature.

\section{MATERIAL AND METHODS}

\subsection{Acid Activation of Vermiculite Samples}

In the study, it was aimed to remove adsorbed components between the layers found in the structure of the clay. For this purpose, analytical techniques were preferred based on the needs of the industry that uses clay according to its surface area. Eventually, the activation process was performed with nitric acid to enable the expansion of the interlayer distance. Clay samples used in the present study were taken from Ordu / Unye region.

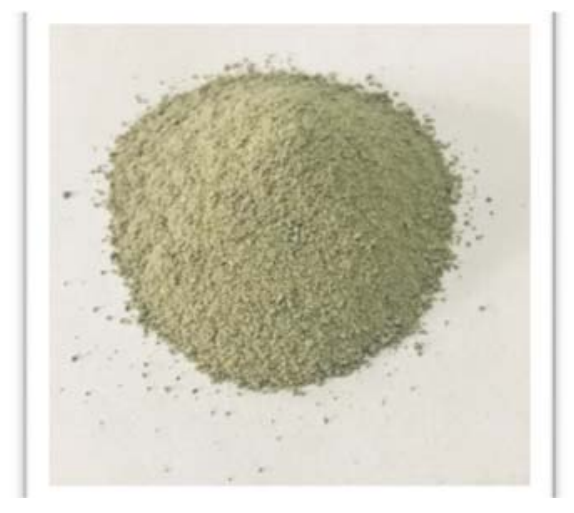

Figure 1. Raw Milled Unye Clay

Approximately $50 \mathrm{~kg}$ of natural clay samples were taken from this sample whose main mineral is vermiculite. This sample was mixed with a sufficient amount of distilled water and then sedimented. Later, the sedimentary clay was subjected to purification. After the sedimentation process, the non-precipitated clay was left to dry. The fully dried sample was ground and made ready for experiments. Using $\mathrm{HNO}_{3}$ at different concentrations $(0.5,1.0,1.5,2.0,3.0), 40$ grams of clay was activated for each concentration. Three different acid groups were prepared (Table 1.). 
Table 1. Composition of different acid groups

\begin{tabular}{cc}
\hline Sample Code & Composition \\
\hline UCA 6 & $2.0 \mathrm{~N}\left(1.0 \mathrm{~N} 200 \mathrm{ml} \mathrm{HCl} \mathrm{\&} 1.0 \mathrm{~N} 200 \mathrm{ml} \mathrm{HNO}_{3}\right)$ \\
UCA 7 & $2.0 \mathrm{~N}\left(1.0 \mathrm{~N} 200 \mathrm{ml} \mathrm{H}_{2} \mathrm{SO}_{4} \& 1.0 \mathrm{~N} 200 \mathrm{ml} \mathrm{HNO}_{3}\right)$ \\
UCA 8 & $2.0 \mathrm{~N}\left(1.0 \mathrm{~N} 200 \mathrm{ml} \mathrm{HCl} \mathrm{\&} 1.0 \mathrm{~N} 200 \mathrm{ml} \mathrm{H}_{2} \mathrm{SO}_{4}\right)$ \\
\hline
\end{tabular}

The samples obtained were subjected to the activation process for 1 hour by refluxing. The mixture was centrifuged at $4000 \mathrm{rpm}$ for 6 hours to make the phase separation of the samples cooled to room temperature. This process was continued until the nitrate ion in the structure was completely removed. The active solid clay samples were dried and ground (under a 200 mesh sieve) and stored in sealed containers for experiments.

\subsection{Characterization of Active Vermiculite Samples}

X-Ray Diffraction method (XRD) was used to determine the mineralogical composition and structural change of the raw and active clay samples. Surface morphologies were visualized by scanning electron microscopy (SEM). Fourier Transform Infrared Spectrophotometer (FTIR) method was used to determine the structural-functional groups. The surface areas of the raw and active clay samples were measured by the Bruneur - Emmet - Teller (BET) method (77 K). Pore distributions were determined with Density Functional Theory Plus (DFT Plus). Surface area measurements of clays were determined on TriStar II Plus device, XRD measurements were determined on Rigaku RadB-DMAX II ( $\mathrm{Cu}$ K-alpha) device, and SEM measurements were determined by Leo EV040 brand scanning electron microscope.

\section{RESULTS AND DISCUSSION}

The surface areas of clays activated with different concentrations of $\mathrm{HNO}_{3}$ are given in Table 2. As given in the table, it was determined that the total surface areas of the activated clay samples varied between $110.30-205.08 \mathrm{~m}^{2} / \mathrm{g}$. Unactivated raw clay has a surface area of 82.77 $\mathrm{m}^{2} / \mathrm{g}$. The minimum surface area was obtained at a concentration of $0.5 \mathrm{~N} \mathrm{HNO}_{3}$. The maximum surface area was obtained with $2 \mathrm{~N} \mathrm{HNO}_{3}$ and its value is $205.08 \mathrm{~m}^{2} / \mathrm{g}$. When the acid concentration was increased, the surface area also increased significantly. At a very high acid concentration, the surface area is partially reduced. When the acid concentration was $3.0 \mathrm{~N}$, the structural collapse occurred and the surface area decreased to $187.22 \mathrm{~m}^{2} / \mathrm{g}$. Clay contains some impurities depending on the geological structure of the region where it is formed. With acid activation, the components between the layers, which are in the structure as impurities, are removed. At this stage, the aim is to increase the structural stability, to remove $\mathrm{M}^{+}, \mathrm{M}^{++}$and $\mathrm{M}^{+++}$ions and organic impurities adsorbed between layers. In addition, as a result of increasing the distance between the layers by the activation process, the adsorption capability of the clay was increased by removing the adsorbed anions existing in the structure from between the layers. The increase in surface area is closely related to the separation of interlayer adsorbed components from the structure. The surface area values determined in our study were compared with similar studies in the literature $\left(\mathrm{H}_{2} \mathrm{SO}_{4}, \mathrm{HNO}_{3}\right.$ and $\mathrm{HCl}$ activated clay) in terms of surface area measurements. Turabik and Kumbur activated the clay surface area by changing the sulfuric acid ratio between 10 and $60 \%$, and the specific surface area increased by a maximum of $40 \%$ [22]. Chmielarz et al. kiln-dried the clay sample with a crude surface area of $8 \mathrm{~m}^{2} / \mathrm{g}$ using nitric acid for 24 hours at $900^{\circ} \mathrm{C}$, and the specific surface area reached a maximum value of $162 \mathrm{~m}^{2} / \mathrm{g}$ [23]. Guerra et al. Activated the specific surface area of $44 \mathrm{~m}^{2} / \mathrm{g}$ in non-treated clay 
with hydrochloric acid to maximize the surface area to $199 \mathrm{~m}^{2} / \mathrm{g}$ [24]. Literature knowledge and the experiments carried out in this study have clearly shown the significance of nitric acid on acid activation. In the activation of clay acid, nitric acid is more effective than sulfuric and hydrochloric acid. The surface areas formed consist of micropores between $46.82-34.60 \mathrm{~m}^{2} / \mathrm{g}$ and mesopores between $169.78-45.71 \mathrm{~m}^{2} / \mathrm{g}$. The increase of mesopore pores is very effective in the large surface areas of clays. In addition, the variation of average pore diameters between $3-6 \mathrm{~nm}$ proves that the clays contain high mesopores.

Table 2. BET analysis results of samples

\begin{tabular}{cccccccc}
\hline Clay Samples & $\begin{array}{c}\text { Surface } \\
\text { Area } \\
\left(\mathbf{m}^{2} / \mathbf{g}\right)\end{array}$ & $\begin{array}{c}\mathbf{S}_{\text {micro }} \\
\left(\mathbf{m}^{2} / \mathbf{g}\right)\end{array}$ & $\begin{array}{c}\mathbf{S}_{\text {meso }} \\
\left(\mathbf{m}^{2} / \mathbf{g}\right)\end{array}$ & $\begin{array}{c}\mathbf{V}_{\mathbf{T}} \\
\left(\mathbf{c m}^{\mathbf{3}} / \mathbf{g}\right)\end{array}$ & $\begin{array}{c}\mathbf{V}_{\text {micro }} \\
\left(\mathbf{c m}^{3} / \mathbf{g}\right)\end{array}$ & $\begin{array}{c}\mathbf{V}_{\text {meso }} \\
\left(\mathbf{c m}^{3} / \mathbf{g}\right)\end{array}$ & $\begin{array}{c}\mathbf{d p} \\
(\mathbf{n m})\end{array}$ \\
\hline UCAH & 82.77 & 53.47 & 29.30 & 0.11 & 0.02 & 0.09 & 5.40 \\
UCA1 (0.5 N) & 110.29 & 45.92 & 72.38 & 0.14 & 0.03 & 0.12 & 4.70 \\
UCA2 (1 N) & 114.46 & 45.19 & 78.89 & 0.15 & 0.03 & 0.12 & 4.54 \\
UCA3 (1.5 N) & 118.39 & 46.82 & 75.86 & 0.15 & 0.03 & 0.11 & 4.58 \\
UCA4 (2 N) & 205.08 & 36.11 & 169.78 & 0.21 & 0.02 & 0.18 & 3.94 \\
UCA5 (3 N) & 172.17 & 35.21 & 152.02 & 0.18 & 0.02 & 0.15 & 3.68 \\
UCA6 & 161.16 & 43.62 & 121.36 & 0.11 & 0.03 & 0.08 & 2.77 \\
UCA7 & 170.85 & 43.17 & 140.64 & 0.18 & 0.02 & 0.16 & 3.88 \\
UCA8 & 148.07 & 45.60 & 100.33 & 0.15 & 0.02 & 0.13 & 4.25 \\
\hline
\end{tabular}

The change in the pore size distribution of raw and acid-activated clay samples is given in Figures 2, 3 and 4, respectively. The pore size distribution of raw clay belongs to pores with maximum 1.6, 2.0, 3.0, 3.5 and $9 \mathrm{~nm}$. According to the results, there is a very heterogeneous pore size distribution between $0-10 \mathrm{~nm}$. Unlike the raw clay sample, it is seen that new pores with 4.0, 5.0 and $8.0 \mathrm{~nm}$ diameter are formed although the pores at $0.5 \mathrm{~N} \mathrm{HNO}_{3}$ concentration are in the range of $0-10 \mathrm{~nm}$. At $1 \mathrm{~N}$ nitric acid concentration, new pores with $5.0 \mathrm{~nm}$ pore diameter are formed compared to the raw sample, while peaks of other pores are seen to be sharpened. In other words, the distribution is seen in a more regular structure. The $1.5 \mathrm{~N}$ nitric acid concentration and the raw clay sample were compared. As a result, new pores with 0.9 , $1.5,4.5 \mathrm{~nm}$ pore sizes were determined. Compared to $2.0 \mathrm{~N}$ nitric acid concentration, while new pores of 2.8 and $8.5 \mathrm{~nm}$ diameters occurred, pores of 3.0 and $9.0 \mathrm{~nm}$ diameters disappeared in the raw clay sample. The $3 \mathrm{~N}$ nitric acid concentration has new pores of 1.0, 2.2 and $3.2 \mathrm{~nm}$ in diameter compared to the raw clay sample. The destruction that occurs in the macromolecular structure of clay can be explained by the formation of new pores in small diameters. Indeed, the smaller surface area is proof of this. In the activation with different acid groups, the pore size distribution in all three acid groups was changed compared to the raw sample, and it was determined that the active clays had pores in the range of 1-10 nm. However, it was determined that the pore size distribution was more regular in the mixture of $\mathrm{HCl}-\mathrm{H}_{2} \mathrm{SO}_{4}$. 


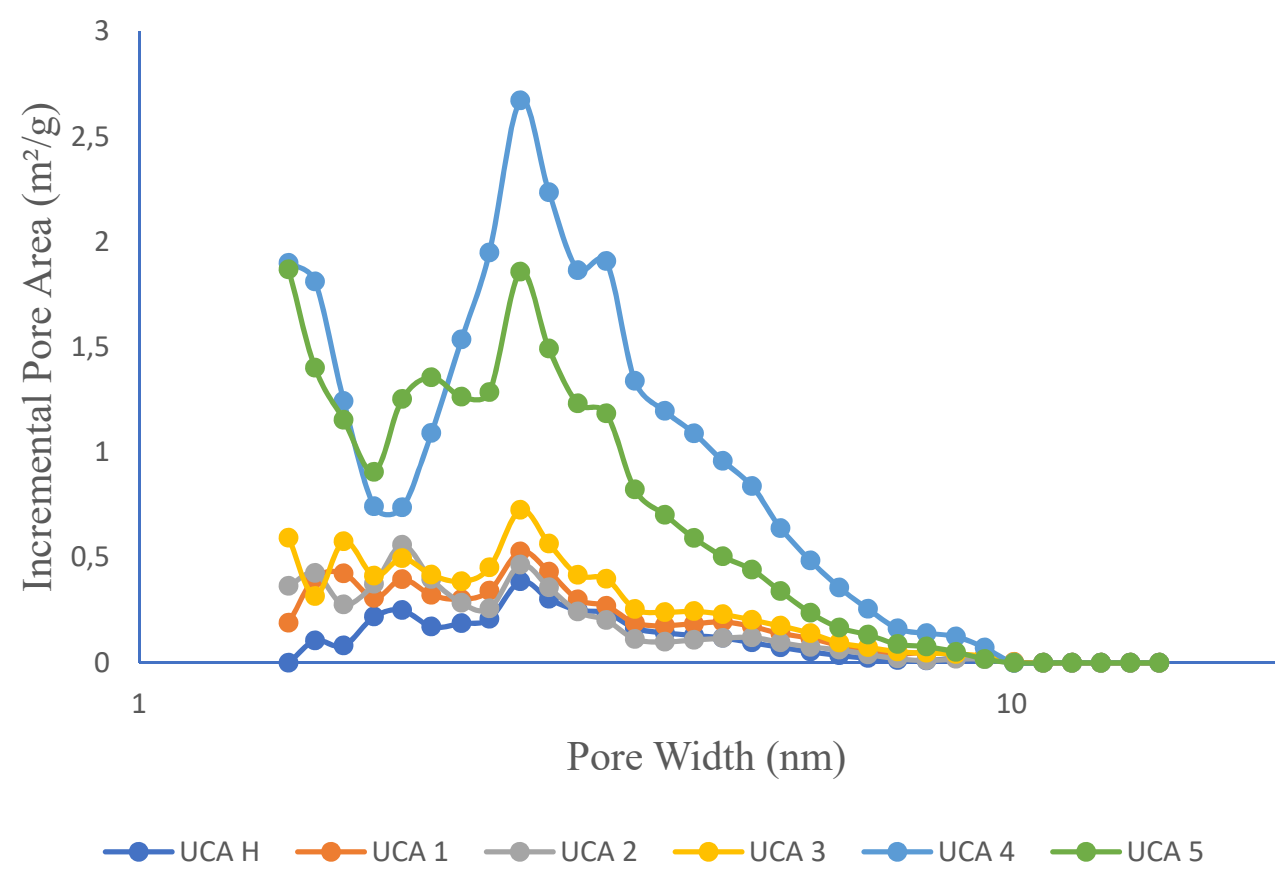

Figure 2. Pore size distribution of raw and $\mathrm{HNO}_{3}$ activated samples DFT Plus isotherm

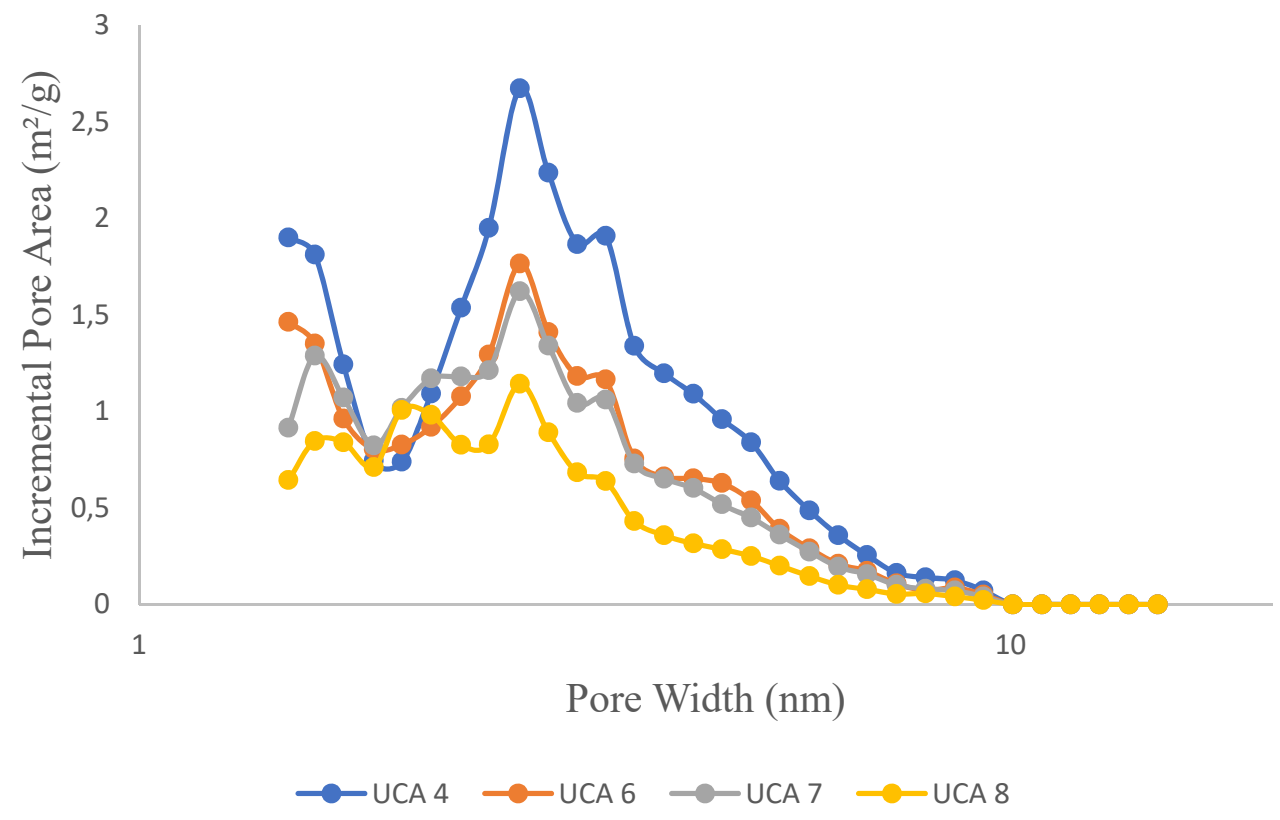

Figure 3. Pore size distribution of samples with high surface area (UCA 4) and activated by different acids DFT Plus isotherm 


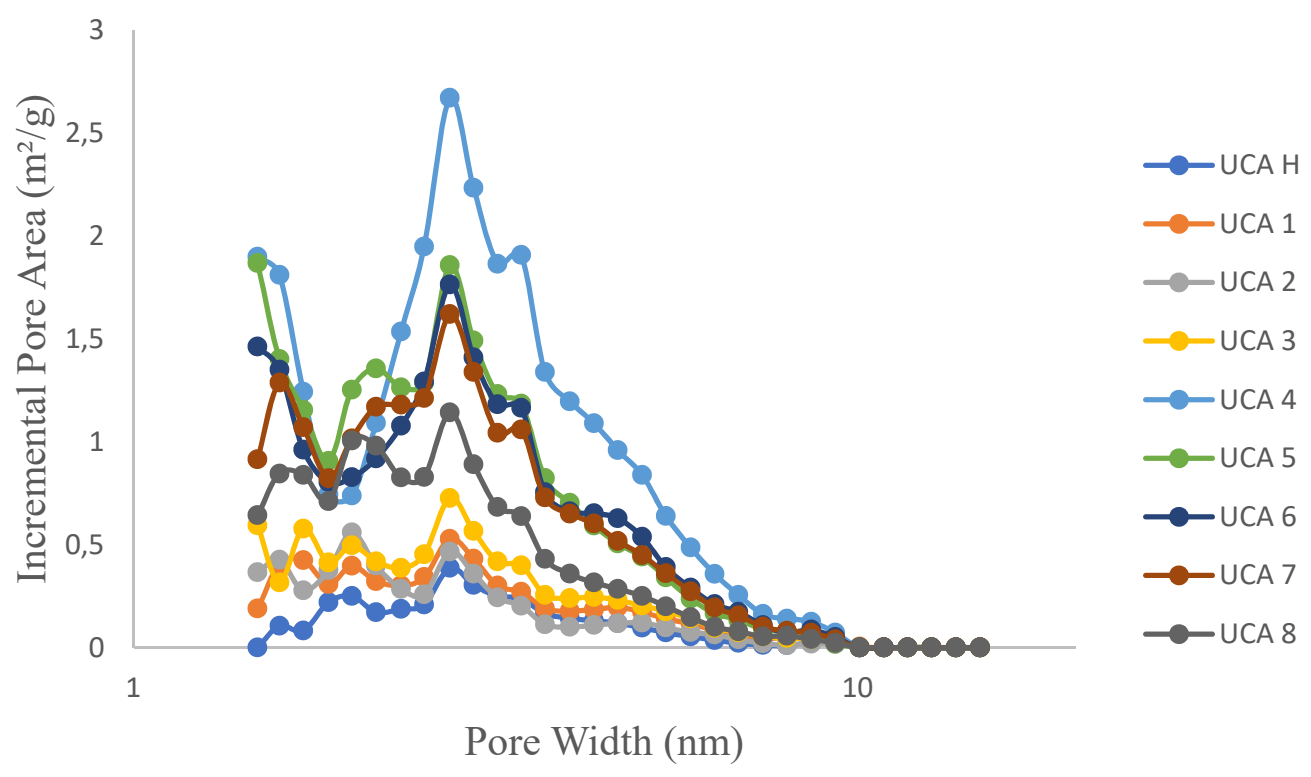

Figure 4. Pore size distribution of samples DFT Plus isotherm

When the nitrogen adsorption isotherm is examined, it is seen that the amount of nitrogen adsorption per gram of clay is seen against the relative pressure $\mathrm{P} / \mathrm{P}_{0}$. Relative pressure ranges from 0 to 1 . The amount of nitrogen adsorption varies according to the surface area of the clay. This change is generally related to the type of porous structure of the clay. When the adsorption isotherms of clays activated with nitric acid are examined, it is observed that they conform to Type 2. This supports the presence of a high amount of mesopore in the isothermal structure. The nitrogen sent to the structure was adsorbed for a while. Type 2 is the S-shaped (sigmoidal) isotherm. The isotherm of nitrogen $(77 \mathrm{~K})$ on many macroporous solids is of this type. BET isotherms are in Type 2 form. According to the BET theory, the adsorbed amounts are the same in all layers except the first layer. Here, the second layer is partially filled before the first layer is filled. The point at the beginning of the midline region is defined as the situation where the monolayer cover is complete and multilayer adsorption is about to begin. However, adsorption continues at all relative pressures.

As a result of the analysis made; while acid concentration increased the surface area increased first, then the surface area decreased at the $3 \mathrm{~N}$ acid concentration. Raw and active clay samples were measured according to Surface Energy Distribution by Modified Density Functional Theory Model: $\mathrm{N}_{2}$ - Modified Density Function software. In addition to being similar to the incremental area-energy change graph, the peak occurring at 40-46 e/k in the entire surface area is similar in all samples. Surface energy remains the same regardless of the increase in surface area. For example, while the raw clay incremental area value shows $42-44$ surface energy in the range of 42.051-62-882, UCA4 sample with the highest surface area gives the same surface energy value between $205.323-56.960 \mathrm{~m}^{2} / \mathrm{g}$. As the active surface area increases as a result of acid activation, the surface energy remain constant can be explained as follows; As a result of the removal of interlayer adsorbed atoms, ions and/or molecules from the structure, negative and positive charge spaces are freed. 


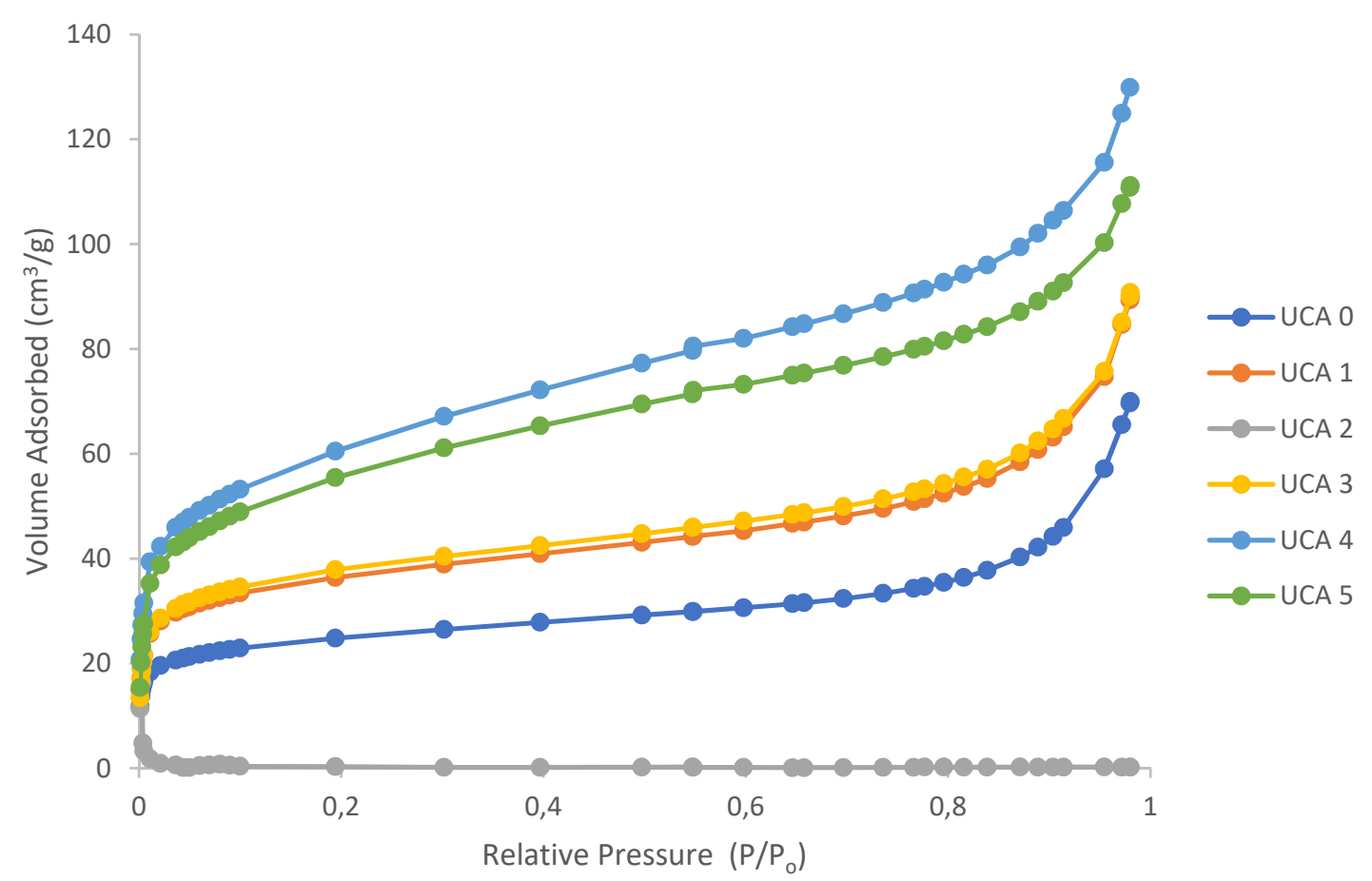

Figure 5. Adsorption isotherms of $\mathrm{N}_{2}$

Table 3. Incremental Surface Area vs. Energy

\begin{tabular}{|c|c|c|c|}
\hline Sample & Energy (e/k) & Sample & Energy (e/k) \\
\hline UCAH & 62 & UCA6 & 145 \\
\hline UCA1 (0.5 N) & 85 & & \\
\hline $\mathrm{UCA2}(1 \mathrm{~N})$ & 88 & UCA7 & 136 \\
\hline $\operatorname{UCA3}(1.5 \mathrm{~N})$ & 98 & & \\
\hline UCA4 (2 N) & 200 & UCA8 & 106 \\
\hline UCA5 (3 N) & 158 & & \\
\hline
\end{tabular}

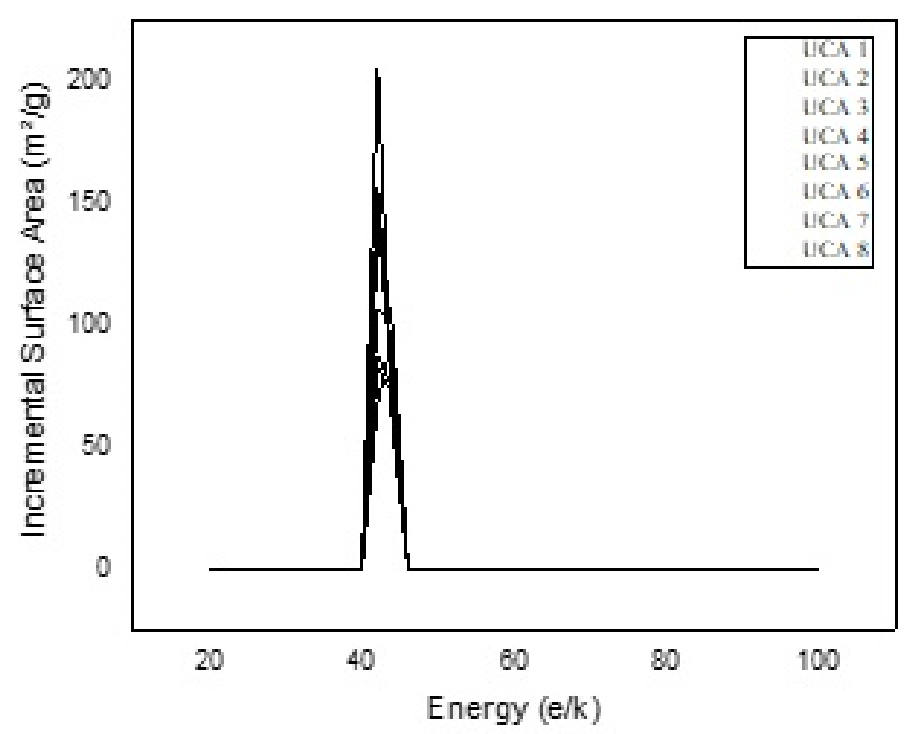

Figure 6. Incremental Surface Area vs. Energy 
XRD patterns of crude and acid-activated clay samples are given in Figures 7 and 8 . When the figure is examined, the distance between the layers of the raw sample of $7.2192 \Theta$ was 12.2334 $\AA$, while this value was obtained as $16.2300 \AA$ in the sample with the highest surface area. This peak area is widening and its height increasing. As a result of the activation, the distance between the layers has increased by $33 \%$. The acid treatment causes a serious change in the crystal structure of the minerals. When Figures 6 and 7 are examined, the high and sharp intensity of around $15.274 \AA$ emerges as a result of $12.883 \AA$ wide and splay peak acid activation in the XRD trace of raw clay. As the cations and other impurities between the layers are removed as a result of the acid treatment, the increase in the $\mathrm{d}$ value between the layers is an expected result. However, as a result of structural degradation in $3 \mathrm{~N} \mathrm{HNO}_{3}$ concentration, the peak decreases to $14.772 \AA$ also the maximum peak value is decreased. When the XRD patterns of a similar study by Chaari et al. [25] are examined, the main impurities in the raw clay are seen with an intense reflection at $2 \Theta=30.5^{\circ}(2.90 \AA)$ and this reflection is dolomite. The pattern shown by sharp (101) basal reflection at $3.34 \AA$ is quartz. The associated minerals detected in small amounts in the same study are basal reflection at $9.99 \AA$ (001), feldspar (feldspars) at $3.23 \AA$ and calcite at $3.03 \AA$. It has been observed that acid activation causes a significant decrease in crystallinity by decreasing the density of smectite and kaolinite. When the XRD traces of Turabik and Kumbur's [22] similar studies were examined, the smectite group was found at $5.88^{\circ}$ and it was understood that it contained crystallite, a silica polymorph, at $21.48^{\circ}$. In addition, $d(001)=15.02 \AA, 18.98 \AA$ and $9.84 \AA$ were obtained. Thus it was found that the original sample was montmorillonite.

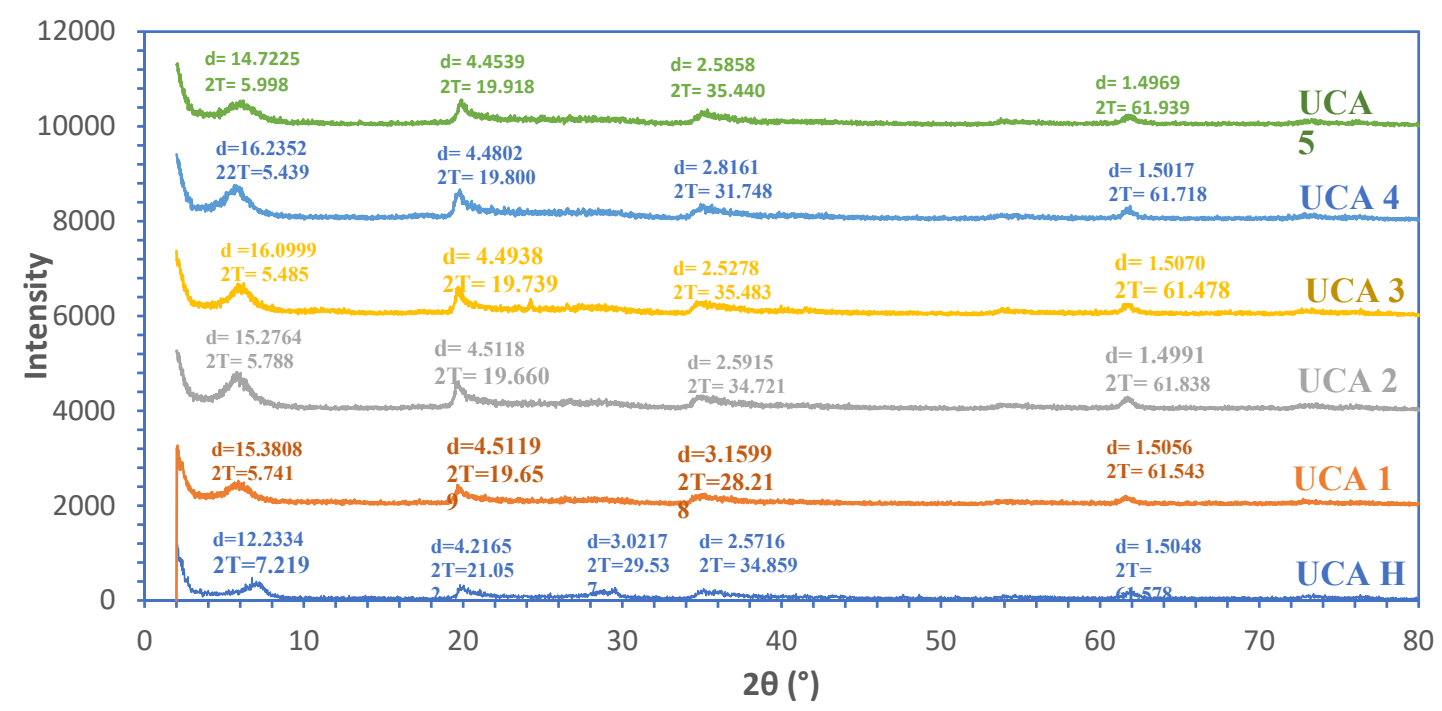

Figure 7. XRD graph of raw and $\mathrm{HNO}_{3}$ activated clays 


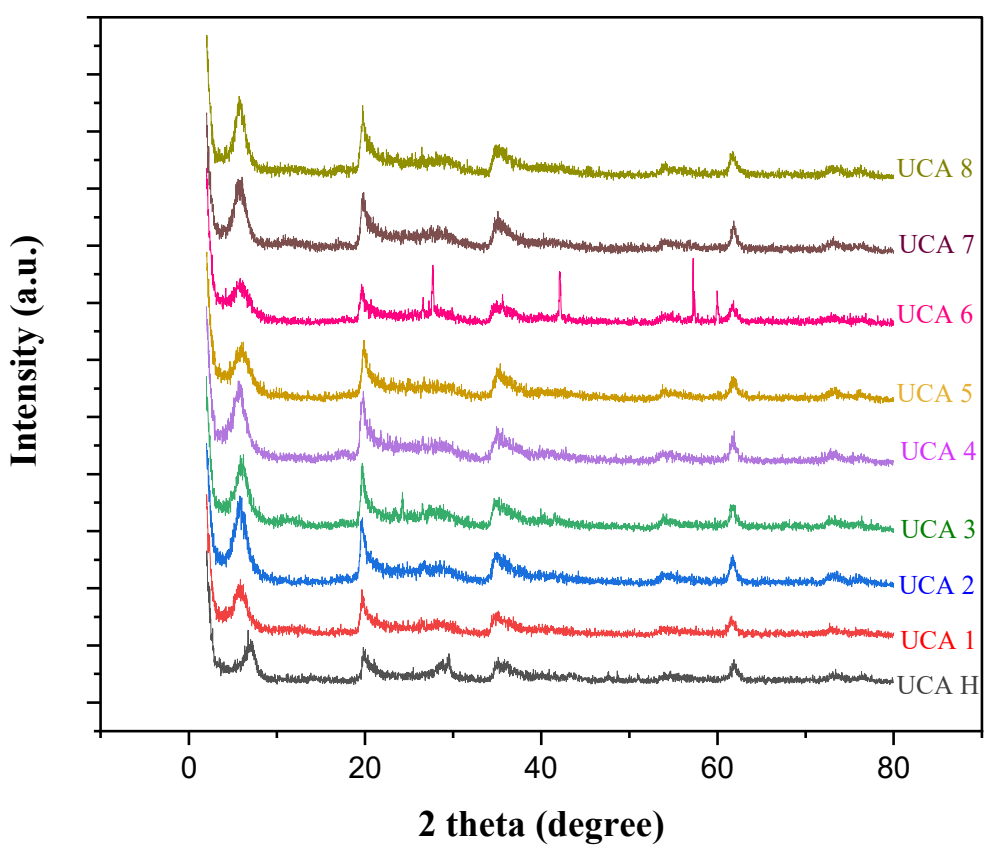

Figure 8. XRD graph of examples

FTIR spectra of the raw and active clay samples are given in Figure 9. When the figure is examined, the bending stress of the $915 \mathrm{~cm}^{-1} \mathrm{Al}-\mathrm{AlOH}$ structure and the 1035 in-plane Si-O stress are seen for the raw sample. The peak occurring in this region is wide. This expansion is explained by the $1113 \mathrm{~cm}^{-1}$ out-of-plane $\mathrm{Si}-\mathrm{O}$ structures in the clay structure and the hydration peak of the $1635 \mathrm{~cm}^{-1}-\mathrm{OH}$ bending. The $-\mathrm{OH}$ stress in the macromolecular main structure of clay minerals is observed in the $3621 \mathrm{~cm}^{-1}$ bands. As the acid concentration increases, the peak in the $700-1300 \mathrm{~cm}^{-1}$ region of the M-O-M stretch in the structure contains 3 shoulders in the range of 711-1189 $\mathrm{cm}^{-1}$ in the raw sample, and also the peak is high and sharp. As the acid concentration increases with acid activation, the peak width of $735-1214 \mathrm{~cm}^{-1}, 728-1214 \mathrm{~cm}^{-1}$, $744-1222 \mathrm{~cm}^{-1}, 744-1271 \mathrm{~cm}^{-1}$ and $735-1271 \mathrm{~cm}^{-1}$ bands are the same, respectively. However, its sharpness and length are different. Since the FTIR traces in this region are related to structures such as $\mathrm{Si}-\mathrm{O}, \mathrm{Si}-\mathrm{O}-\mathrm{Si}, \mathrm{Al}-\mathrm{O}, \mathrm{Al}-\mathrm{O}-\mathrm{Al}$ and these groups are the basic building blocks of clay, it is an expected result that these peaks remain largely unchanged. The $-\mathrm{OH}$ stretching observed around $1630 \mathrm{~cm}^{-1}$ is a group in the mineralogical structure of the clay mineral and is observed in all acid concentrations. It belongs to the $-\mathrm{OH}$ stress of water adsorbed by wide and flat peak clay around $3300 \mathrm{~cm}^{-1}$. The $-\mathrm{OH}$ stress of $3630 \mathrm{~cm}^{-1}$ belonging to the mineralogical structure of clay is quite distinct and sharp in the raw sample, and it is partially deformed and shrunk as a result of acid activation [26-27]. 


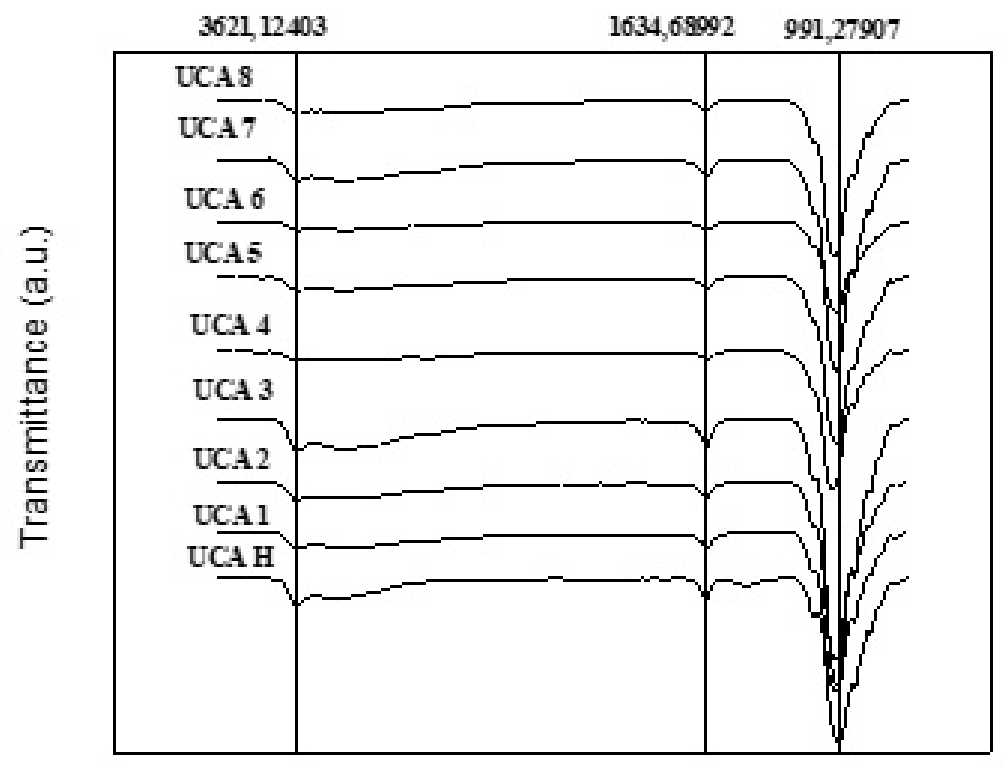

Wavenumber $\left(\mathrm{cm}^{-1}\right)$

Figure 9. FTIR graph of examples

SEM images of raw and active clay samples are given in Figures 10 and 11. When SEM images are examined, it is seen that the raw clay sample has a very homogeneous structure and does not contain any impurities. This is an expected result as impurities are removed from the structure with sedimentation. Clay layers are visible and different grain sizes show the same structure with each other. It is seen that there are important changes within the structural units as a result of acid activation. In the example of UCA $4\left(2 \mathrm{~N} \mathrm{HNO}_{3}\right)$ with the highest surface area, it was determined that the structural units shrunk, the inter-layer units were seen, and as a result, the surface area increased. However, in the example of UCA $5\left(3 \mathrm{~N} \mathrm{HNO}_{3}\right)$, the surface area decreases as a result of high acid concentration and as seen in the SEM image, it is seen that cavities are formed between the units similar to the graphene structure. Although the concentration is low in the mixture of $\mathrm{HCl}-\mathrm{HNO}_{3}$, the structural units of the clay mineral are seen as a whole. The morphological structure of the UCA 7 sample is similar to the $\mathrm{HNO}_{3}$ activation only. In the mixture of UCA 8, it is seen that the structural units are separated from each other and that graphene-like formations appear. This structure is similar to UCA 5, and when the acid is strong, the macromolecular structure is affected. 

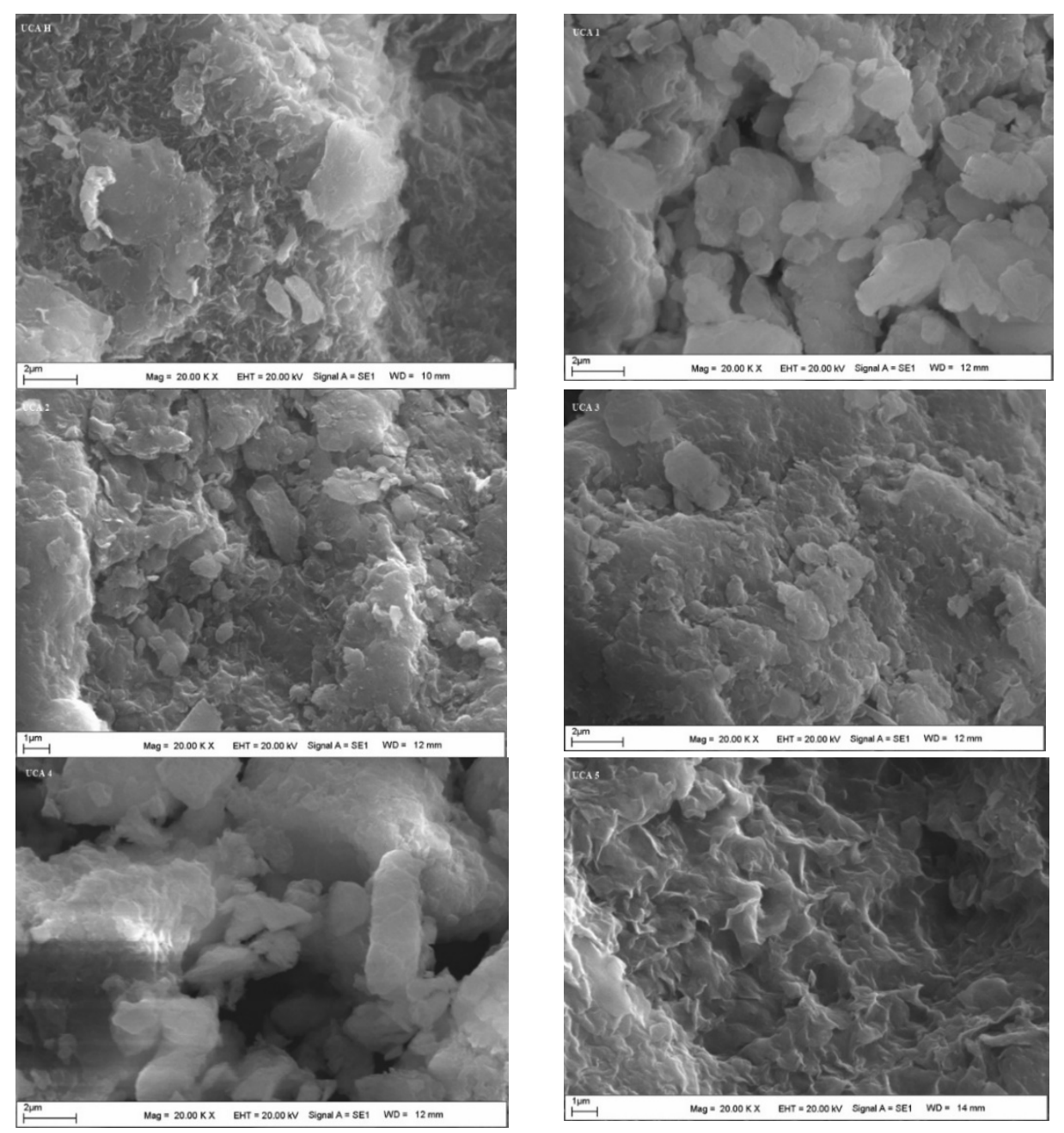

Figure 10. SEM images of raw and $\mathrm{HNO}_{3}$ activated clays
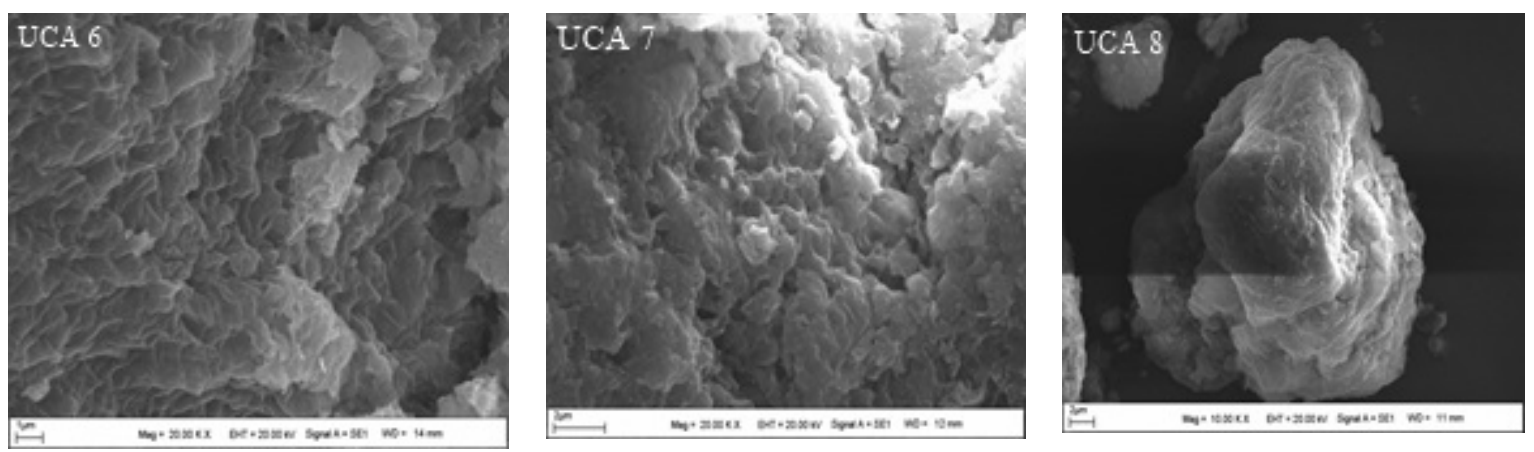

Figure 11. SEM images of clays activated by different acids

a. UCA $6\left(\mathrm{HCl}-\mathrm{HNO}_{3}\right)$ b. UCA $7\left(\mathrm{H}_{2} \mathrm{SO}_{4}-\mathrm{HNO}_{3}\right)$ c. UCA $8\left(\mathrm{HCl}-\mathrm{H}_{2} \mathrm{SO}_{4}\right)$ 


\section{CONCLUSIONS}

In this study, the highest surface area change in acid activation with nitric acid was obtained as $150 \%$ at $2 \mathrm{~N} \mathrm{HNO}_{3}$ concentration. The smallest change was obtained at a concentration of $34 \%$ and $0.5 \mathrm{~N} \mathrm{HNO}_{3}$. Generally, the higher the nitric acid concentration, the higher the surface area, and the lower the surface area at the $3 \mathrm{~N} \mathrm{HNO}_{3}$ concentration. At this concentration, the mass loss by weight is $13.55 \%$. Therefore, the macromolecular structure of the clay at high acid concentration is lost. Structural change is seen in XRD diffractograms. As the acid concentration increases, it is seen that the clay layers appear more clearly in SEM images. In addition, as the acid concentration increases, it has been determined that the structural degradation increases in the $3 \mathrm{~N} \mathrm{HNO}_{3}$ concentration. Structural change in terms of functional groups with changing acid concentration gave similar results to XRD and SEM results in FTIR spectrum. The highest surface area in different acid groups was obtained in the mixture of $1 \mathrm{~N}$ $\mathrm{HCl}$ and $1 \mathrm{~N} \mathrm{HNO}_{3}$. Nitric acid is environmentally important in the acid activation of clay samples, and when diluted sufficiently at the end of the wash, it will not have any negative effects on the nitrate ion, on the contrary, it will be an important nutritional component for plants.

\section{Acknowledgments}

We would like to thank Altaş Oil industry company for the clay samples.

\section{REFERENCES}

[1] Santos, S.S.G., Silva, H.R.M., Souza, de A.G., Alves, A.P.M., Silva Filho, da E.C. and Fonseca, M.G. (2015). Acid-leached mixed vermiculites obtained by treatment with nitric acid, Applied Clay Science, 104: 286294.

[2] Krupskayaa, V., Novikovad, L., Tyupinaee, E., Belousova, P., Dorzhievaa, O., Zakusina, S., Kimh, K., Roessneri, F., Badettij, E., Brunellij, A., and Belchinskayad, L. (2019). The influence of acid modification on the structure of montmorillonites and surface properties of bentonites, Applied Clay Science, 172: 1-10.

[3] Komadel, P. (2016). Acid activated clays: Materials in continuous demand, Applied Clay Science, 131: 8499.

[4] Krupskaya, V., Novikovad, L., Tyupinae, E., Belousova, P., Dorzhievaa, O., Zakusina, S., Kimh, K., Roessneri, F., Badettij, E., Brunellij, A., and Belchinskayad, L. (2019). The influence of acid modification on the structure of montmorillonites and surface properties of bentonites, Applied Clay Science, 172: 1-10.

[5] Lycourghiotis, S., Makarouni, D., Kordouli, E., Bourikasa, K., Kordulis, C., and Dourtoglou, V. (2018). Activation of natural mordenite by various acids: Characterization and evaluation in the transformation of limonene into p-cymene, Molecular Catalysis, 450: 95-103.

[6] Guerra, D.L., Lemos, V.P., Airoldi, C., and Ange'lica, R.S. (2006). Influence of the acid activation of pillared smectites from Amazon (Brazil) in adsorption process with butylamine, Polyhedron, 25: 2880-2890

[7] Hussin, F., Aroua, M.K., and Wan Mohd Ashri Wan Daud, WMAW. (2011). Textural characteristics, surface chemistry and activation of bleaching earth: A review, Chemical Engineering Journal, 170: 90-106.

[8] Steudel, A., Batenburg, L.F., Fischer, H.R., Weidler, P.G., and Emmerich, K. (2009). Alteration of swelling clay minerals by acid activation, Applied Clay Science, 44: 105-115. 
[9] Komadel, P., and Madejová, J. (2013). Acid Activation of Clay Minerals, Handbook of Clay Science, Developments in Clay Science, 5: 385-409.

[10] Juang, R.S., Wu, F.C., and Tseng, R.L. (2010). Acid activated clays: Materials in continuous demand, Environmental Technology, 18: 525-531.

[11] Carrado, K.A., and Komadel, P. (2009). Acid Activation of Bentonites and Polymer-Clay Nanocomposites, Elements, 5: 111-116.

[12] Vicente Rodríguez, M.A., López González, J.de D., and Bañares Muñoz, M.A. (1995). Preparation of microporous solids by acid treatment of a saponite, Microporous Materials, 4: 251-264.

[13] Komadel, P. (2003). Chemically modified smectites, Clay Minerals, 38: 127-138.

[14] Balc1, S. (2018). Structural Property Improvements of Bentonite with Sulfuric Acid Activation, Journal of the Turkish Chemical Society Section B: Chemical Engineering, 1(2): 201-212.

[15] Sabah, E. (2007). Decolorization of vegetable oils: Chlorophyll-a adsorption by acid-activated sepiolite, Journal of Colloid and Interface Science, 310: 1-7.

[16] Burst, J.F. (1991).The application of clay minerals in ceramics, Applied Clay Science, 5 (5-6): 421-443.

[17] Sousa, P. de E., Araujo, T. de D., Peixoto, G.V., Ferreira, F.B., Faria, H. de E., and Molina, F.E. (2020). Effect of sodium bentonite content on structural-properties of ureasil poly (ethylene oxide)-PEO hybrid: A perspective for water treatment, Applied Clay Science, 191: 105605.

[18] Chmielarz, L., Wojciechowska, M., Rutkowska, M., Adamski, A., Węgrzyn, A., Kowalczyk, A., Dudek B., Boroń, P., Michalik, M., and Matusiewicz, A. (2012). Acid-activated vermiculites as catalysts of the DeNO $\mathrm{N}_{\mathrm{x}}$ process, Catalysis Today, 191(1): 25-31.

[19] Ravichandran, J., Lakshmanan, C.M., and Sivasankar, B. (1996). Acid Activated Montmorillonite and Vermiculite Clays as Dehydration and Cracking Catalysts, Reaction Kinetics and Catalysis Letters, 59: 301308.

[20] Ravichandran, J., and Sivasankar, B. (1997). Properties and Catalytic Activity of Acid-Modified Montmorillonite and Vermiculite, Clays and Clay Minerals, 45: 854-858.

[21] Caglar, B., Afsin, B., Koksal, E., Tabak, A., and Eren, E. (2013). Characterization of Unye Bentonite After Treatment with Sulfuric Acid, Química Nova, 36(7): 955-959.

[22] Turabik, M., and Kumbur, H. (2002). Change in some Physicochemical properties of Ünye/Ordu bentonite with acid activation, Cumhuriyet Üniversitesi Mühendislik Fakültesi Dergisi, 19: 1-10.

[23] Chmielarz, L., Kowalczyk, A., Michalik, M., Dudek, B., Piwowarska, Z., and Matusiewicz, A. (2010). Acidactivated vermiculites and phlogophites as catalysts for the DeNOx process, Applied Clay Science, 49: 156162.

[24] Guerra, D.L., Lemos, V.P., Airoldi, C., and Ange'lica, R.S. (2006). Influence of the acid activation of pillared smectites from Amazon (Brazil) in adsorption process with butylamine, Polyhedron, 25: 2880-2890.

[25] Chaari, I., Medhiou, M., Jamoussi, F., and Hamzaoui, A.H. (2021). Acid-treated clay materials (Southwestern Tunisia) for removing sodium leuco-vat dye: Characterization, adsorption study and activation mechanism, Journal of Molecular Structure, 1223: 128944.

[26] Tyagi, B., Chudasama, C.D., and Jasra, R.V. (2006). Determination of structural modification in acid activated montmorillonite clay by FT-IR spectroscopy, Spectrochimica Acta Part A: Molecular and Biomolecular Spectroscopy, 64(2): 273-278.

[27] Snoussi, Y., Khalil, A.M., Strzemiecka, B., Voelkel, A., and Chehimi, M.M. (2017). Surface Analysis of Clay Polymer Nanocomposites, Clay Polymer Nanocomposite, 11: 363-411. 